\title{
Modification of the glass transitions of polymers by high-pressure gas solubility*
}

\author{
Séverine A. E. Boyer and J.-P. E. Grolier ${ }^{\ddagger}$ \\ Laboratoire de Thermodynamique des Solutions et des Polymères, \\ Université Blaise Pascal, 63177 Aubière, France
}

\begin{abstract}
The newly developed VW- $p V T$ technique for simultaneously measuring the solubility of a gas in a polymer and the concomitant change of volume of the polymer has been used to estimate the solubilities of $\mathrm{N}_{2}, \mathrm{CO}_{2}$, and two hydrofluorocarbons, HFC-134a and HFC-152a, in polystyrene (PS). In conjunction with these solubility data, Chow's model has been used to calculate the change of the glass-transition temperature of the polymer resulting from gas sorption. The performance of this model for predicting the glass-transition temperature shift is then discussed.
\end{abstract}

Keywords: polystyrene; glass transition; gas solubility; carbon dioxide; nitrogen; HFC-134a; HFC-152a.

\section{INTRODUCTION}

Polymer foaming is currently achieved in various ways, but typically involves elevated temperatures and pressures as well as the addition of chemicals, mostly gases that are used as blowing agents. Thermal, mechanical, and/or chemical stress may shift, even permanently, the polymer glass-transition temperature, $T_{\mathrm{g}}$; such shifts consequently affect the physical properties of the material. The sorption of fluids, including gases in the supercritical state, induces significant plasticization, resulting in a substantial decrease of the glass-transition temperature. Such effects are rather weak when using helium or nitrogen due to their low solubility in polymers [1] but sufficiently high pressures should induce higher gas sorption [2]. In this respect, gases such as carbon dioxide or hydrofluorocarbons (HFCs) are known to be good fluids for plasticization of polymers like polystyrene (PS).

As a result of increasing international regulation, gases used up to now for foaming have to be replaced by blowing agents that are less harmful to the Earth's ozone layer. The present work takes place in the context of this very active field of research. Knowledge of $T_{\mathrm{g}}$ of a \{polymer + gas $\}$ system is of real importance because the sorption of gas, and the concomitant swelling of the polymer below and above this temperature, yields different types of foams. Moreover, many properties of the system can be correlated with the $T_{\mathrm{g}}$ depression associated with plasticization. Systems of \{polymer + gas $\}$ under controlled pressure, heated above $T_{\mathrm{g}}$ have to be depressurized in order to quickly "freeze" the structure of the foam so formed. Determination of $T_{\mathrm{g}}$, which will govern the state of the system, is then essential to control the foaming process. The behavior of the \{polymer + gas $\}$ systems presented in this work has been previously described [3].

\footnotetext{
*Paper based on a presentation at the $11^{\text {th }}$ International Symposium on Solubility Phenomena (1 ${ }^{\text {th }}$ ISSP), Aveiro, Portugal, 25-29 July 2004. Other presentations are published in this issue, pp. 513-665.

¥Corresponding author
} 
Different models have been proposed in the literature to predict $T_{\mathrm{g}}$. They are essentially of two types: either based on the Gibbs and Di Marzio principle [4], like Chow's model [5], or directly derived from lattice theory like the model used by Condo et al. [6]. Chow's model was developed on the assumption, after Gibbs and Di Marzio, of the entropy being zero at $T_{\mathrm{g}}$. This model has been used particularly to study the rheology of \{polymer + gas \} mixtures $[7,8]$. In the present investigation, Chow's model has been used to evaluate the pressure dependence of the $T_{\mathrm{g}}$ shift resulting from the sorption of the diluent gas for four different $\{$ polymer + gas $\}$ systems: $\left\{\mathrm{PS}+\mathrm{N}_{2}\right\},\left\{\mathrm{PS}+\mathrm{CO}_{2}\right\},\{\mathrm{PS}+\mathrm{HFC}-134 \mathrm{a}\}$, and $\{\mathrm{PS}+\mathrm{HFC}-152 \mathrm{a}\}$. This has been done as a function of pressure, at pressures higher than those usually considered in the literature. The determination of the $T_{\mathrm{g}}$ at these high pressures has been possible using the gas solubility obtained with a recently developed instrument [9]. The results have been compared to data from the literature and those recently obtained in our laboratory. The capability of Chow's model to predict the $T_{\mathrm{g}}$ shift is discussed.

\section{CHOW'S MODEL}

Chow has proposed a relation, based on the Gibbs and Di Marzio principle [4], to account for the change in $T_{\mathrm{g}}$ due to the absorbed component as follows:

$$
\ln \left(\frac{T_{g}}{T_{g 0}}\right)=\beta[(1-\theta) \ln (1-\theta)+\theta \ln \theta]
$$

where:

$$
\beta=\frac{z R}{M_{\mathrm{p}} \Delta C_{\mathrm{p}}} \quad \theta=\frac{M_{\mathrm{p}}}{z M_{\mathrm{d}}} \frac{\omega}{1-\omega}
$$

$T_{\mathrm{g}}$ and $T_{\mathrm{g} 0}$ are the glass-transition temperatures for the $\{$ polymer + gas $\}$ system and the pure polymer, respectively; $M_{\mathrm{p}}$ is the molar mass of the polymer repeat unit; $M_{\mathrm{d}}$ is the molar mass of the (diluent) gas; $R$ is the gas constant; $\omega$ is the mass fraction of the gas in the polymer; $\Delta C_{\mathrm{p}}$ is the heat capacity change associated with the glass transition of the pure polymer; and $z$ is the lattice coordination number. All parameters of the model have real and known physical significance, except the number $z$. The value of this parameter may change according to the state of the diluent: $z=2$ when the diluent is in the liquid state [5] and $z=1$ for a gas [1]. Gendron et al. [8] have estimated that a value of $z=2$ is appropriate for diluent with a molecular weight of about $75-250 \mathrm{~g} \mathrm{~mol}^{-1}$. This should be the case for the HFCs studied, but not for $\mathrm{N}_{2}$ and $\mathrm{CO}_{2}$. In the case of $\mathrm{CO}_{2}$, Chow has still suggested a value of 2 for this parameter, whereas Chiou et al. [1] and Handa et al. [10] have found a better agreement with the experimental data when using a value of $z=1$.

In this work, we compare the results when using both values of $z$ for all fluids except for nitrogen, for which a value of 1 has been used because of the very small molecular weight.

\section{EXPERIMENTAL}

The samples of PS used in this present work were supplied by ATOFINA France, with the reference "Lacqrene 1450N", in the form of cylindrical pellets, with a diameter and a height of about $2 \mathrm{~mm}$. The average molecular weight of the PS, measured by size exclusion chromatography, was $\bar{M}_{\omega}=190000 \mathrm{~g}$ $\mathrm{mol}^{-1}$ with a dispersion index $I_{\mathrm{p}}=2.7$. The $\mathrm{CO}_{2}$ and $\mathrm{N}_{2}$ were supplied by SAGA, France with respective purities of 99.5 and $99.95 \%$. The HFC-134a and HFC-152a were supplied by Elf ATOCHEM France. All chemicals were used as received.

The experimental technique used to determine the solubility has been described in detail by Hilic et al. [9]. The experimental set-up consists of an original coupling of two techniques, a vibrating-wire 
(VW) sensor to weigh the polymer sample during sorption and a pressure-decay $p V T$ technique to evaluate the quantity of gas, transferred from a high-pressure calibrated cell, which has been absorbed by the polymer sample. A schematic view of the VW sensor, which constitutes the core of the experimental set-up, is shown in Fig. 1. It is essentially a high-pressure cell in which the polymer sample is placed in a holder suspended by a thin tungsten wire (diameter $25 \mu \mathrm{m}$, length $30 \mathrm{~mm}$ ) in such a way that the wire is positioned in the middle of a high magnetic field generated by a square magnet placed across the high-pressure cell. Through appropriate electric circuitry and electronic control, the tungsten wire is activated to vibrate. The period of vibration that can be accurately measured is directly related to the mass of the suspended sample. Coupling of the $p V T$ and VW techniques allows simultaneous evaluation of the quantity of gas absorbed by the polymer as well as the polymer swelling during the sorption process. A recent reevaluation of the coupled VW- $p V T$ technique has shown that the size and geometry of the samples do not affect the results [11].

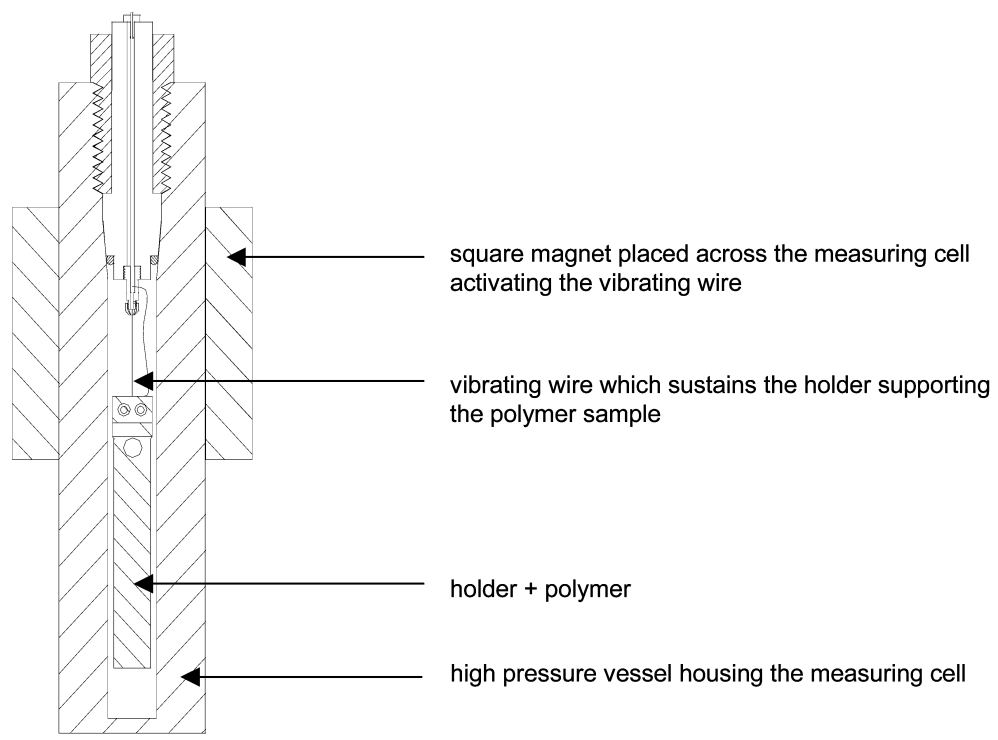

Fig. 1 Schematic view showing the main parts of the VW sensor and $p V T$-cell.

In the present study, for each sorption isotherm, a new polymer sample of about $5 \mathrm{~g}$ was introduced in the sample holder. After stabilization of the temperature, the working gas pressure was attained step by step to ensure perfect equilibrium. Several isotherms at given equilibrium pressures have been performed for each fluid. For $\mathrm{CO}_{2}$, four measurements have been made at 338.22, 362.50, 383.22, and 402.51; for $\mathrm{N}_{2}$, three temperatures have been investigated, $313.11,333.23$, and $353.15 \mathrm{~K}$; concerning the hydrofluorocarbons, HFC-134a was measured at 385.34 and $402.94 \mathrm{~K}$ and HFC-152a at $413.15 \mathrm{~K}$. The experimental conditions and the solubility data for $\mathrm{CO}_{2}$ and $\mathrm{N}_{2}$ have been previously published [3]. The solubility data for HFC-134a and for HFC-152a are given in Table 1.

To use Chow's model, it was necessary to characterize the glass transition of the nonmodified polymer in terms of $T_{\mathrm{g}}$, and to estimate the change in heat capacity, $\Delta C_{\mathrm{p}}$, between the glassy and the liquid state. At atmospheric pressure, $T_{\mathrm{g} 0}$ of PS and the corresponding $\Delta C_{\mathrm{p}}$ have been determined using a modulated-temperature thermal analyzer ADSC 821 from Mettler-Toledo. This instrument allows detection of glass transition phenomena [2], and $T_{\mathrm{g}}=378.15 \mathrm{~K}$ and $\Delta C_{\mathrm{p}}=0.22 \mathrm{~K}$ were obtained, respectively. The experimental conditions used were a heating rate $q=2 \mathrm{~K} \mathrm{~min}^{-1}$ and an amplitude of modulation $A_{\mathrm{T}}=0.5 \mathrm{~K}$ with a period $p=60 \mathrm{~s}$.

For comparing the results with experimental calorimetric data, we have modified similar PS samples using scanning transitiometry, which combines a calorimetric detector with a high pressure system. 
This technique and the experimental conditions have been previously described [12]. As a matter of fact, a scanning transitiometer has been used for the present work as a small reactor to modify PS samples under equilibrium conditions in the presence of the chosen fluid. Modifications of PS have been made with HFC-134a and HFC-152a, at isotherms at the selected pressure. For the two fluids, a final temperature of $398.15 \mathrm{~K}$ and a final pressure of $8 \mathrm{MPa}$ have been attained. Modified PS samples were then analyzed using the ADSC technique, under the same conditions as those described above for the nonmodified PS.

Table 1 Solubility data in $\mathrm{g}(\mathrm{gas}) / \mathrm{g}(\mathrm{PS})$ of $\{\mathrm{PS}+\mathrm{HFC}-134 \mathrm{a}\}$ at 385.34 and $402.94 \mathrm{~K}$, and of $\{$ PS + HFC-152a $\}$ at $413.15 \mathrm{~K}$.

\begin{tabular}{|c|c|c|c|c|c|}
\hline \multicolumn{2}{|c|}{$\mathrm{PS}+\mathrm{HFC}-134 \mathrm{a}$} $385.34 \mathrm{~K}$ & \multicolumn{2}{|c|}{$\mathrm{PS}+\mathrm{HFC}-134 \mathrm{a}$} $402.94 \mathrm{~K}$ & \multicolumn{2}{|c|}{$\mathrm{PS}+\mathrm{HFC}-152 \mathrm{a}$} $413.15 \mathrm{~K}$ \\
\hline$p / \mathrm{MPa}$ & $s / 10^{3}(\mathrm{~g} / \mathrm{g})$ & $p / \mathrm{MPa}$ & $s / 10^{3}(\mathrm{~g} / \mathrm{g})$ & $p / \mathrm{MPa}$ & $s / 10^{3}(\mathrm{~g} / \mathrm{g})$ \\
\hline 2.99 & 59.55 & 3.40 & 61.55 & 3.68 & 59.72 \\
\hline 4.39 & 104.20 & 5.02 & 81.53 & 5.98 & 171.81 \\
\hline 7.18 & 126.98 & 8.87 & 115.43 & 7.24 & 377.63 \\
\hline 9.04 & 144.11 & 15.22 & 140.80 & 8.31 & 374.60 \\
\hline 11.89 & 144.69 & 19.88 & 158.47 & & \\
\hline 15.48 & 154.54 & & & & \\
\hline
\end{tabular}

\section{RESULTS AND DISCUSSION}

The sorption of the gases was measured for different isotherms; the mass fraction of the gas in the polymer was then determined with eq. 2 :

$$
\omega=\frac{s}{s+1}
$$

$s$ being the solubility of the fluid in the polymer, in $\mathrm{mg}$ (fluid)/mg(polymer).

Using the values of $\omega$ so determined for each \{PS + gas $\}$ system, Chow's equation (1) has permitted estimation of the variation, $\Delta T_{\mathrm{g}}$, of the glass-transition temperature with pressure along the different isotherms of the sorption measurements. The calculated values of $\Delta T_{\mathrm{g}}$ are reported in Tables 2-4 for the respective systems: $\left\{\mathrm{PS}+\mathrm{N}_{2}\right\},\left\{\mathrm{PS}+\mathrm{CO}_{2}\right\},\{\mathrm{PS}+\mathrm{HFC}-134 \mathrm{a}$ and $+\mathrm{HFC}-152 \mathrm{a}\}$. Following Gendron et al. [8], we have used a value of $z=1$ for $\mathrm{N}_{2}$ because of its low molecular weight. For the other systems, both values ( 1 and 2 ) of $z$ have been used for comparison. Results are presented in Figs. 2-5, for $\mathrm{N}_{2}, \mathrm{CO}_{2}, \mathrm{HFC}-134 \mathrm{a}$, and HFC-152a respectively, and compared with available literature values. For the two systems $\left\{\mathrm{PS}+\mathrm{N}_{2}\right\}$ and $\{\mathrm{PS}+\mathrm{HFC}-152 \mathrm{a}\}$, no data have been found in the literature for comparison. For the two systems $\left\{\mathrm{PS}+\mathrm{CO}_{2}\right\}$ and $\{\mathrm{PS}+\mathrm{HFC}-134 \mathrm{a}\}$, two calorimetric studies have been reported [13,14]. Zang and Handa [14] have shown that for $\left\{\mathrm{PS}+\mathrm{CO}_{2}\right\}$, the variation of $T_{\mathrm{g}}$ is noticeably similar when performing an experiment under a given pressure or when running it at atmospheric pressure, using for this purpose the polymer previously saturated at the same pressure. Following the same idea, we have modified PS samples under specific conditions of temperature and pressure using a scanning transitiometer as a reactor. At $398.15 \mathrm{~K}$, a pressure of $8.0 \mathrm{MPa}$ has been applied to the systems $\{$ PS + HFC-134a $\}$ and $\{$ PS + HFC-152a $\}$. The modified PS samples were analyzed by ADSC to evaluate the variation of $T_{\mathrm{g}}$. The corresponding curves are presented in Fig. 6 and the calculated values of $\Delta T_{\mathrm{g}}$ (Table 4) are reported in Figs. 4 and 5. 
Table 2 Calculated values of the variations of the temperature of the glass transition, $\Delta T_{\mathrm{g}}$, for the system $\left\{\mathrm{PS}+\mathrm{N}_{2}\right\}$ as a function of pressure for the three isotherms, 313.11, 333.23, and $353.15 \mathrm{~K}$ of experimental measurements of solubilities [3]. Calculations have been made for $z=1$, using eqs. 1 and 2 .

\begin{tabular}{cccccc}
\hline$p / \mathrm{MPa}$ & $\Delta T_{\mathrm{g}} / \mathrm{K}$ & $p / \mathrm{MPa}$ & $\Delta T_{\mathrm{g}} / \mathrm{K}$ & $p / \mathrm{MPa}$ & $\Delta T_{\mathrm{g}} / \mathrm{K}$ \\
\hline $313.11 \mathrm{~K}$ & \multicolumn{2}{c}{$333.23 \mathrm{~K}$} & \multicolumn{2}{c}{$353.15 \mathrm{~K}$} \\
3.11 & -7.4 & 3.05 & -4.2 & 3.29 & -5.6 \\
5.32 & -10.7 & 6.43 & -7.9 & 7.00 & -9.2 \\
6.90 & -12.5 & 9.82 & -12.7 & 10.42 & -12.5 \\
9.15 & -14.1 & 13.47 & -16.2 & 13.95 & -14.3 \\
10.88 & -16.5 & 16.43 & -18.6 & 17.26 & -17.0 \\
14.26 & -19.9 & 20.29 & -21.5 & 21.38 & -18.9 \\
18.17 & -23.0 & 24.34 & -25.7 & 25.35 & -21.7 \\
22.11 & -25.2 & 28.13 & -28.9 & 30.26 & -22.9 \\
26.64 & -28.7 & 32.54 & -29.9 & 35.10 & -24.8 \\
31.74 & -32.5 & 37.31 & -32.7 & 40.12 & -27.3 \\
46.77 & -41.7 & 41.54 & -35.5 & 44.76 & -29.1 \\
69.47 & -47.2 & 45.84 & -37.7 & 49.27 & -32.0 \\
& & 50.12 & -40.8 & 53.00 & -34.2 \\
& & & & 58.40 & -35.7 \\
& & & & 62.50 & -37.2 \\
\hline
\end{tabular}

Table 3 Calculated values of the variations of the temperature of the glass transition, $\Delta T_{\mathrm{g}}$, for the system $\left\{\mathrm{PS}+\mathrm{CO}_{2}\right\}$ as a function of pressure for the four isotherms, 338.22, $362.50,383.22$, and $402.51 \mathrm{~K}$ of experimental measurements of solubilities [3]. Calculations have been made for $z=1$ and $z=2$, using eqs. 1 and 2 .

\begin{tabular}{|c|c|c|c|c|c|c|c|}
\hline$p / \mathrm{MPa}$ & $\Delta T_{\mathrm{g}} / \mathrm{K}$ & $p / \mathrm{MPa}$ & $\Delta T_{\mathrm{g}} / \mathrm{K}$ & $p / \mathrm{MPa}$ & $\Delta T_{\mathrm{g}} / \mathrm{K}$ & $p / \mathrm{MPa}$ & $\Delta T_{\mathrm{g}} / \mathrm{K}$ \\
\hline \multicolumn{8}{|c|}{$z=1$} \\
\hline \multicolumn{2}{|c|}{$338.22 \mathrm{~K}$} & \multicolumn{2}{|c|}{$362.50 \mathrm{~K}$} & \multicolumn{2}{|c|}{$383.22 \mathrm{~K}$} & \multicolumn{2}{|c|}{$402.51 \mathrm{~K}$} \\
\hline 3.71 & -38.69 & 4.30 & -39.02 & 6.55 & -37.88 & 5.14 & -20.07 \\
\hline 7.54 & -58.80 & 8.09 & -53.22 & 11.04 & -51.09 & 9.39 & -43.21 \\
\hline 10.25 & -66.48 & 11.47 & -63.89 & 14.51 & -58.63 & 21.48 & -66.78 \\
\hline 11.96 & -69.88 & 14.15 & -68.72 & 17.66 & -65.67 & 33.05 & -76.82 \\
\hline 16.54 & -77.60 & 16.50 & -73.90 & 20.42 & -69.61 & 44.41 & -79.18 \\
\hline 18.33 & -78.91 & 18.92 & -75.92 & 23.55 & -72.66 & & \\
\hline \multirow[t]{5}{*}{24.52} & -80.34 & 21.60 & -77.56 & 27.03 & -74.30 & & \\
\hline & & 24.65 & -78.70 & 30.61 & -77.44 & & \\
\hline & & & & 34.38 & -78.51 & & \\
\hline & & & & 38.63 & -79.51 & & \\
\hline & & & & 42.81 & -80.91 & & \\
\hline
\end{tabular}


Table 3 (Continued).

\begin{tabular}{|c|c|c|c|c|c|c|c|}
\hline$p / \mathrm{MPa}$ & $\Delta T_{\mathrm{g}} / \mathrm{K}$ & $p / \mathrm{MPa}$ & $\Delta T_{\mathrm{g}} / \mathrm{K}$ & $p / \mathrm{MPa}$ & $\Delta T_{\mathrm{g}} / \mathrm{K}$ & $p / \mathrm{MPa}$ & $\Delta T_{\mathrm{g}} / \mathrm{K}$ \\
\hline \multicolumn{8}{|c|}{$z=2$} \\
\hline \multicolumn{2}{|c|}{$338.22 \mathrm{~K}$} & \multicolumn{2}{|c|}{$362.50 \mathrm{~K}$} & \multicolumn{2}{|c|}{$383.22 \mathrm{~K}$} & \multicolumn{2}{|c|}{$402.51 \mathrm{~K}$} \\
\hline 3.71 & -44.5 & 4.30 & -44.9 & 6.55 & -43.5 & 5.14 & -22.2 \\
\hline 7.54 & -70.8 & 8.09 & -63.1 & 11.04 & -60.3 & 9.39 & -50.1 \\
\hline 10.25 & -81.9 & 11.47 & -78.1 & 14.51 & -70.5 & 21.48 & -82.4 \\
\hline 11.96 & -87.2 & 14.15 & -85.4 & 17.66 & -80.7 & 33.05 & -99.3 \\
\hline 16.54 & -100.9 & 16.50 & -93.9 & 20.42 & -86.8 & 44.41 & -104.2 \\
\hline 18.33 & -103.6 & 18.92 & -97.6 & 23.55 & -91.8 & & \\
\hline \multirow[t]{5}{*}{24.52} & -106.9 & 21.60 & -100.8 & 27.03 & -94.7 & & \\
\hline & & 24.65 & -103.2 & 30.61 & -100.5 & & \\
\hline & & & & 34.38 & -102.8 & & \\
\hline & & & & 38.63 & -104.9 & & \\
\hline & & & & 42.81 & -108.3 & & \\
\hline
\end{tabular}

Table 4 Calculated values of the variations of the temperature of the glass transition, $\Delta T_{\mathrm{g}}$, for the systems $\{\mathrm{PS}+\mathrm{HFC}-134 \mathrm{a}\}$ and $\{$ PS + HFC-152a , respectively, as function of pressure: for the two isotherms 385.34 and $402.94 \mathrm{~K}$ for HFC-134a and for the isotherm $413.15 \mathrm{~K}$ for HFC-152a, along which the corresponding solubilities (listed in Table 1) have been determined. Calculations have been made for $z=1$ and $z=2$, using eqs. 1 and 2.

\begin{tabular}{|c|c|c|c|c|c|}
\hline \multicolumn{4}{|c|}{ HFC-134a } & \multicolumn{2}{|c|}{ HFC-152a } \\
\hline$p / \mathrm{MPa}$ & $\Delta T_{\mathrm{g}} / \mathrm{K}$ & $p / \mathrm{MPa}$ & $\Delta T_{\mathrm{g}} / \mathrm{K}$ & $p / \mathrm{MPa}$ & $\Delta T_{\mathrm{g}} / \mathrm{K}$ \\
\hline \multicolumn{6}{|c|}{$z=1$} \\
\hline \multicolumn{2}{|c|}{$385.34 \mathrm{~K}$} & \multicolumn{2}{|c|}{$402.94 \mathrm{~K}$} & \multicolumn{2}{|c|}{$413.15 \mathrm{~K}$} \\
\hline 2.99 & -30.2 & 3.40 & -30.9 & 3.68 & -42.4 \\
\hline 4.39 & -43.7 & 5.02 & -37.3 & 5.98 & -73.8 \\
\hline 7.18 & -49.4 & 8.87 & -46.6 & 7.24 & -81.0 \\
\hline 9.04 & -53.1 & 15.22 & -52.4 & 8.31 & -80.2 \\
\hline 11.89 & -53.3 & 19.88 & -56.1 & & \\
\hline 15.48 & -55.3 & & & & \\
\hline \multicolumn{6}{|c|}{$z=2$} \\
\hline \multicolumn{2}{|c|}{$385.34 \mathrm{~K}$} & \multicolumn{2}{|c|}{$402.94 \mathrm{~K}$} & \multicolumn{2}{|c|}{$413.15 \mathrm{~K}$} \\
\hline 2.99 & -34.07 & 3.40 & -34.9 & 3.68 & -49.1 \\
\hline 4.39 & -50.76 & 5.02 & -42.8 & 5.98 & -93.7 \\
\hline 7.18 & -58.00 & 8.87 & -54.4 & 7.24 & -131.9 \\
\hline 9.04 & -63.01 & 15.22 & -62.1 & 8.31 & -132.9 \\
\hline 11.89 & -63.17 & 19.88 & -67.0 & & \\
\hline 15.48 & -65.90 & & & & \\
\hline
\end{tabular}




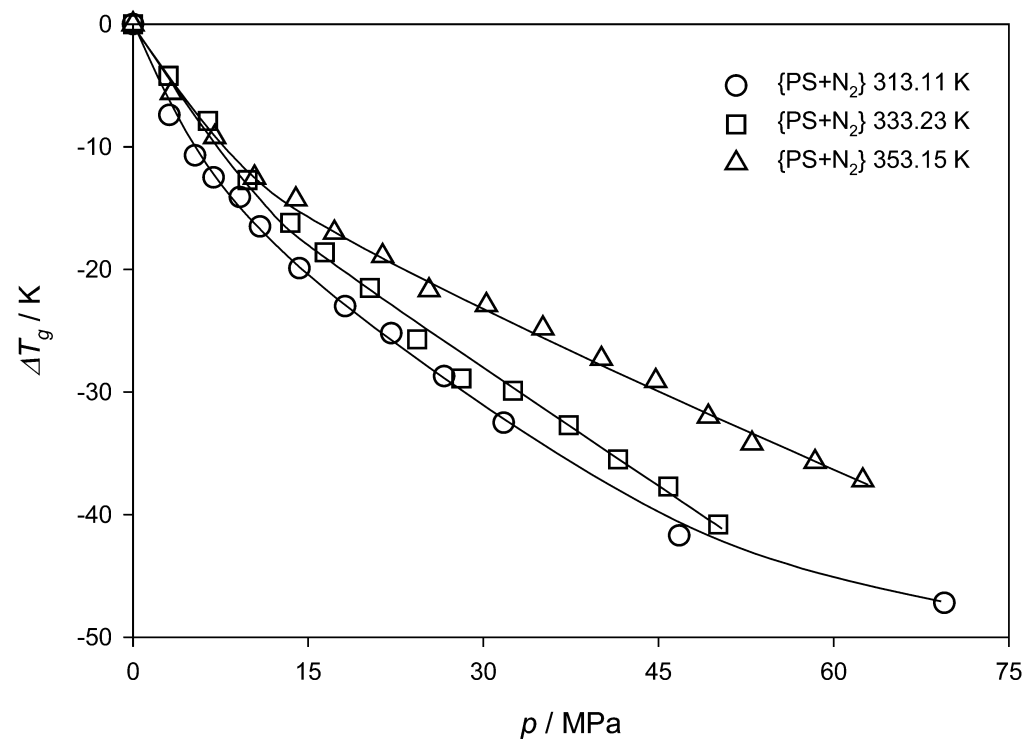

Fig. 2 Variation of the glass-transition temperature as a function of pressure for the system $\left\{P S+N_{2}\right\}$. Calculations have been made for the three temperatures of experimental measurements: $313.11,333.23$, and $353.15 \mathrm{~K}$, using $z=1$. Symbols represent calculated values. Curves are lines of best fit through the points.

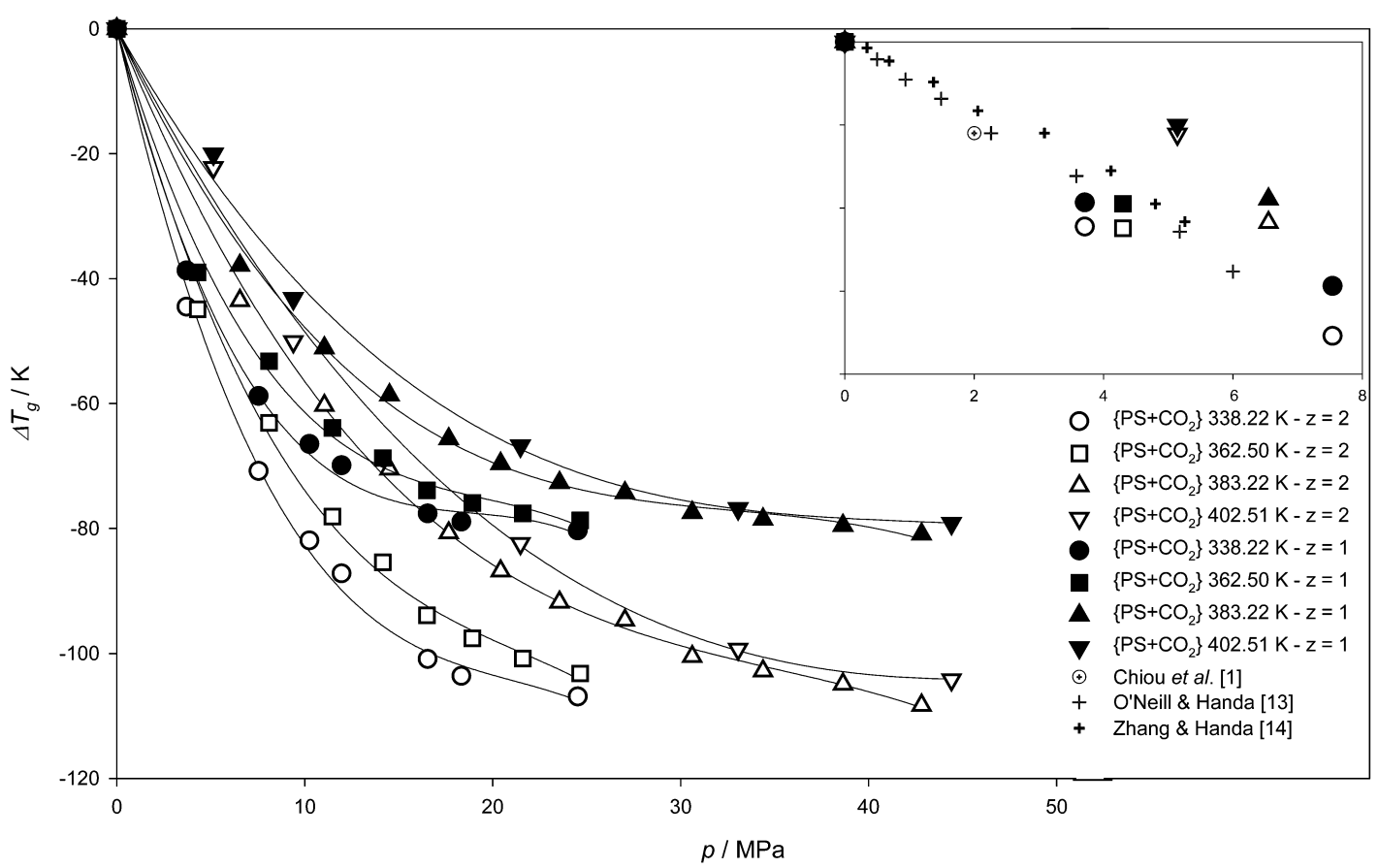

Fig. 3 Variation of the glass-transition temperature as a function of pressure for the system $\left\{\mathrm{PS}+\mathrm{CO}_{2}\right\}$. Calculations have been made for the four temperatures: $338.22,362.50,383.22$, and $402.51 \mathrm{~K}$, of experimental measurements. Full symbols represent results for $z=1$ and empty symbols results for $z=2$. Literature values are represented by crosses in the inset of the graph (the same scale being kept for temperature). Curves are lines of best fit through the points. 


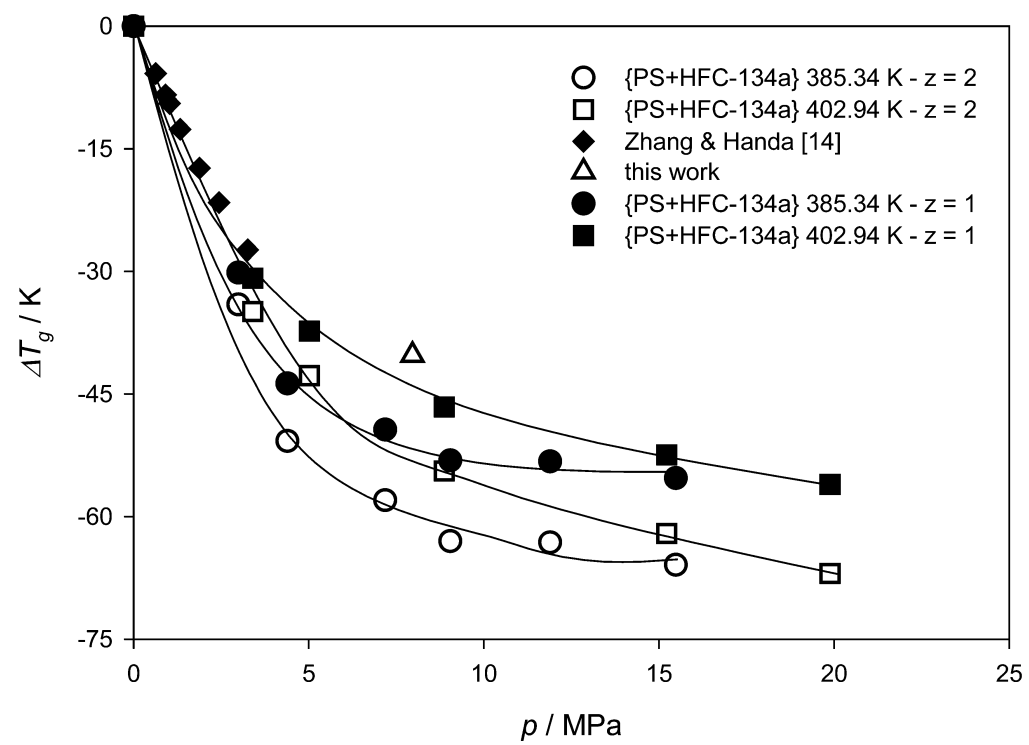

Fig. 4 Variation of the glass-transition temperature as a function of pressure for the system $\{$ PS + HFC-134a . Calculations have been made for the two temperatures: 385.34 and $402.94 \mathrm{~K}$, of experimental measurements. and $\boldsymbol{\square}$, results for $z=1$; $\bigcirc$ and $\square$, results for $z=2$; $\diamond$, literature values; $\triangle$, present experimental work. Curves are lines of best fit through the points.

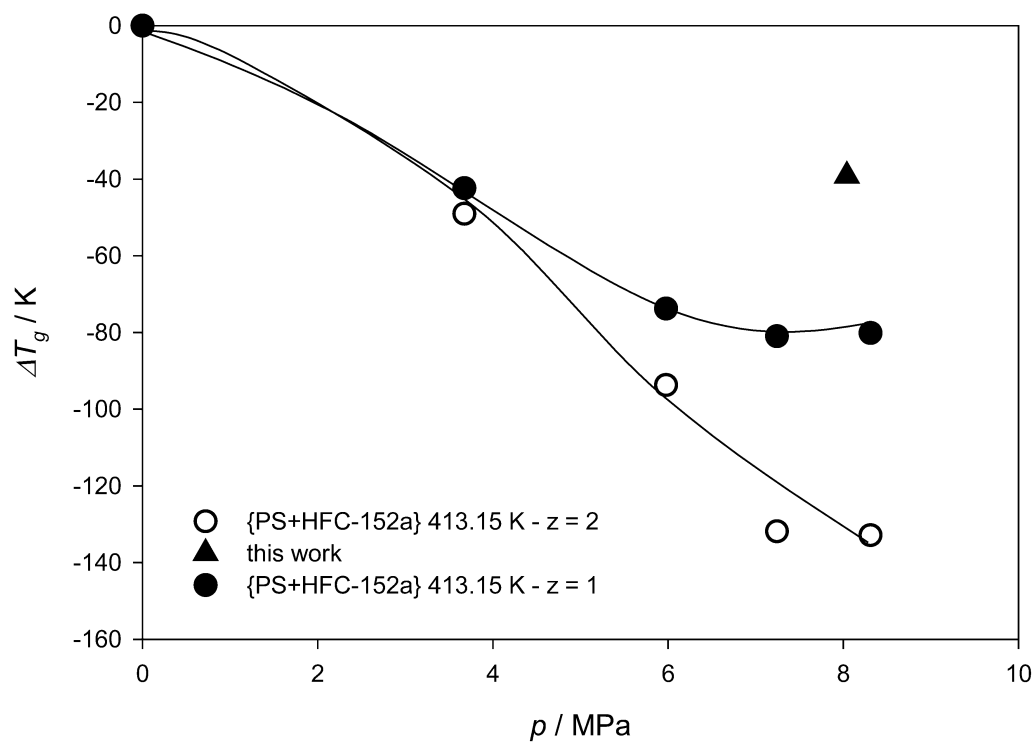

Fig. 5 Variation of the glass-transition temperature as a function of pressure for the system $\{$ PS + HFC-152a $\}$. Calculations have been made at the temperature: $413.15 \mathrm{~K}$, of experimental measurements. $\bullet$, results for $z=1$; $\bigcirc$, results for $z=2 ; \boldsymbol{\Delta}$, present experimental work. Curves are lines of best fit through the points.

As shown by Figs. 3-6, the value of $z$ has a large influence on the results. A difference of up to $60 \mathrm{~K}$ for $T_{\mathrm{g}}$ is obtained at the highest pressures, with greater variation being observed when the diluent is in the liquid state. However, since only data at relatively low pressures are available for the system $\left\{\mathrm{PS}+\mathrm{CO}_{2}\right\}$, we cannot make a clear choice of $z$ value. As shown by Fig. 3, the experimental data found in the literature fall between the extreme values of $z=1$ or 2 . In the inset of Fig. 3, the literature data 


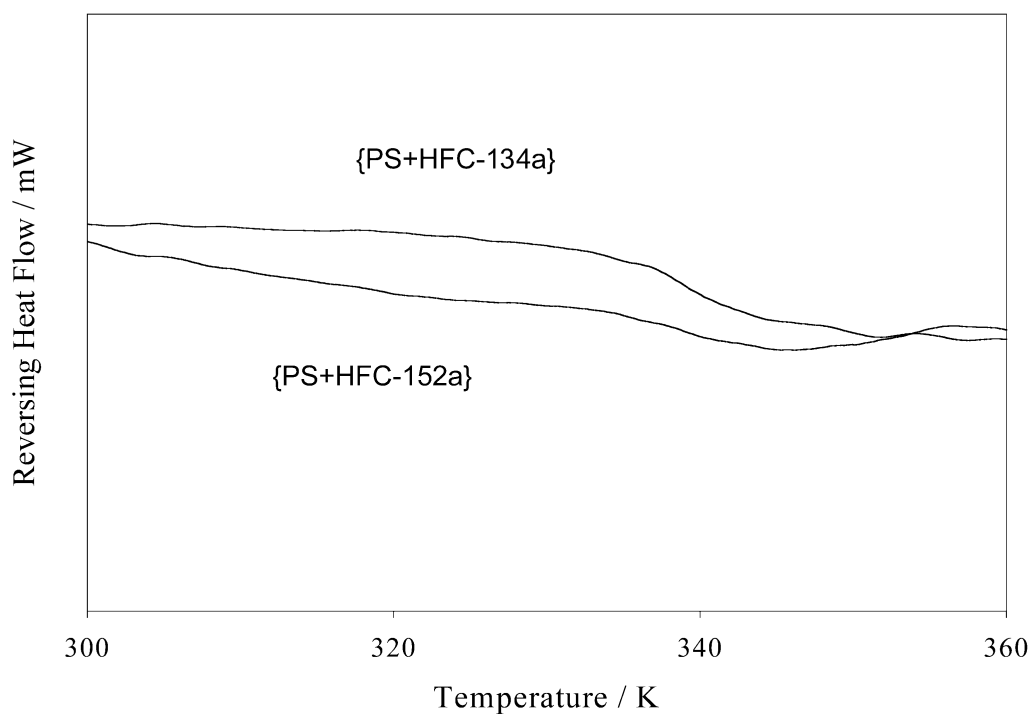

Fig. 6 Reversing heat flow signals showing the glass-transition domains of PS samples saturated with either HFC-134a or HFC-152a under 8.0 MPa. Measurements have been made at atmospheric pressure with a MettlerToledo ADSC 821 thermal analyzer.

have been plotted, keeping the same scale for $\Delta T_{\mathrm{g}}$ for the two series of calculated data that show the largest deviations in the range $0-10 \mathrm{MPa}$.

As concerns the system $\{$ PS + HFC-134a $\}$, the literature values in the low-pressure range can be fitted with both values of $z$. However, our single experimental point at higher pressure is closer to the results obtained at about the same temperature, $402.94 \mathrm{~K}$, for $z=1$. The same observation is made with the system $\{$ PS + HFC-152a , but there is a large difference between the unique experimental point and the calculated data. This difference probably results partly from discrepancies between the experimental solubility data (literature and present) and partly from the solubility decrease with increasing temperature $[3,15]$ yielding a small change of $T_{\mathrm{g}}$ at higher temperature.

The use of Chow's model is then rather delicate because the choice of the value of $z$, i.e., the state of the diluent, significantly influences the results. The good agreement between the calculated and literature values for $\left\{\mathrm{PS}+\mathrm{CO}_{2}\right\}$ and $\{\mathrm{PS}+\mathrm{HFC}-134 \mathrm{a}\}$ can certainly be explained by the state of the diluent which is in the (near) critical state in the ranges of $T$ and $p$ considered (Table 5). Depending on the conditions around $T_{\mathrm{c}}$ and $p_{\mathrm{c}}$ and especially close to the critical point, the fluid can exist in one or in the other state (gas or liquid) or even in both. In the present case, literature data for the two systems $\left\{\mathrm{PS}+\mathrm{CO}_{2}\right\}$ and $\{\mathrm{PS}+\mathrm{HFC}-134 \mathrm{a}\}$ have been obtained under a pressure $p \leq p_{\mathrm{c}}$ and at either a temperature $T \geq T_{\mathrm{c}}$ for $\mathrm{CO}_{2}$ or $T \leq T_{\mathrm{c}}$ for HFC-134a, respectively, then the two phases of the diluent can coexist in different proportions. Under our experimental conditions for the two HFCs, i.e., $398 \mathrm{~K}$

Table 5 Critical temperatures and pressures of $\mathrm{N}_{2}, \mathrm{CO}_{2}, \mathrm{HFC}-134 \mathrm{a}$, and HFC-152a.

\begin{tabular}{lcc}
\hline Fluid & $p_{\mathrm{c}} / \mathrm{MPa}$ & $T_{\mathrm{c}} / \mathrm{K}$ \\
\hline $\mathrm{N}_{2}$ & 3.398 & 126.19 \\
$\mathrm{CO}_{2}$ & 7.375 & 304.13 \\
HFC-134a & 4.056 & 374.18 \\
HFC-152a & 4.495 & 386.41 \\
\hline
\end{tabular}


and 8.0 MPa, they should be in the supercritical state, since the temperature is close to their critical temperatures (Table 5). However, it is likely to correspond to a state with the density of the liquid and the viscosity of the gas, the variation of their respective proportions being important near the critical point.

Despite the difficulty of determining exactly the variation of $T_{\mathrm{g}}$, particularly under supercritical conditions for the diluent fluid, Chow's model can still be used to estimate this variation, and to compare different fluids to assess their efficiency as plasticizers. From the present work, it appears that the variation of $T_{\mathrm{g}}$ as a function of pressure is more important when using HFC-152a, which is indeed one of best fluids currently available for foaming polymer materials. From this point of view, $\mathrm{CO}_{2}$ seems also to be a good plasticizing agent. Because of its nonpolarizability, $\mathrm{N}_{2}$ should be a weaker plasticizing agent. This means that care should be taken when arguing about the variation of $T_{\mathrm{g}}$ as a function of the solubility of the gas in the polymer and, correspondingly, the importance of the mass fraction $\omega$. In this respect, $\mathrm{N}_{2}$ appears to be a better plasticizing agent followed, in sequence of decreasing efficiency, by $\mathrm{CO}_{2}$, HFC-152a, and HFC-134a. One must consider that both the solubility of the penetrant fluid and the glass transition of the amorphous polymer are affected not only by the nature of the interactions between the solubilized fluid and the polymer, but also by the molecular structure and geometry of the fluid. A flexible molecule has a larger plasticizing efficiency than a stiff one. In fact, concentration, size, and flexibility are of great importance in determining the depression of $T_{\mathrm{g}}$ [4]. When two fluids exhibit the same solubility, the smaller the size of the penetrating molecule, the higher is the plasticization effect. However, $\mathrm{N}_{2}$, which would be a good candidate for foaming, is not used in the foaming industry because of the need of too high a pressure to attain the desired depression of $T_{\mathrm{g}}$.

\section{CONCLUSION}

Chow's model is a useful guide for predicting the variation of the glass transition of a polymer modified by a high-pressure fluid. However, the exact determination of the glass-transition temperature depression, $\Delta T_{\mathrm{g}}$, becomes more difficult when the pressure increases, especially near and above the critical point of the diluent fluid. Plotting $\Delta T_{\mathrm{g}}$ as a function of pressure stresses the importance of the measurement temperature. If the measurement temperature is not the main factor, it is preferable to represent $\Delta T_{\mathrm{g}}$ as a function of the mass fraction of the gas in the polymer.

\section{ACKNOWLEDGMENTS}

Financial support through the Brite Euram Program No. 97-4154 "Interactions between gases and polymers at high pressures. Polymer foaming process" is highly appreciated. The help of Dr. S. L. Randzio from Institute of Physical Chemistry of the Polish Academy of Science in Warsaw, in performing the transitiometric measurements, is also gratefully acknowledged.

\section{REFERENCES}

1. J. S. Chiou, J. W. Barlow, D. R. Paul. J. Appl. Polym. Sci. 30, 2633 (1985).

2. M. Ribeiro, L. Pacinsky, J.-P. E. Grolier. Polymer 42, 1653 (2001).

3. S. Hilic, S. A. E. Boyer, A. A. H. Padua, J.-P. E. Grolier. J. Polym. Sci., Part B: Polym. Phys. 39, 2063 (2001).

4. J. H. Gibbs and E. A. Di Marzio. J. Chem. Phys. 28, 373 (1958).

5. T. S. Chow. Macromolecules 13, 362 (1980).

6. P. D. Condo, I. C. Sanchez, C. G. Panayiotou, K. P. Johnston. Macromolecules 25, 6119 (1992).

7. Y. Mi, S. Zhou, S. A. Stern. Macromolecules 24, 2361 (1992).

8. R. Gendron, L. E. Daigneault, L. M. Caron. J. Cell. Plastic 35, 221 (1999).

9. S. Hilic, A. A. H. Padua, J.-P. E. Grolier. Rev. Sci. Instrum. 71, 4236 (2000). 
10. Y. P. Handa, S. Capowski, M. L. O'Neill. Thermochim. Acta 226, 177 (1993).

11. S. A. E. Boyer and J.-P. E. Grolier. Polymer (2005). In press.

12. S. L. Randzio and J.-P. E. Grolier. Anal. Chem. 70, 2327 (1998).

13. M. L. O'Neill and Y. P. Handa. In Assignment of the Glass Transition, R. J. Seyler (Ed.), pp. 165-173, ASTM, Philadelphia (1994).

14. Z. Zang and Y. P. Handa. J. Polym. Sci., Part B: Polym. Phys. 36, 977 (1998).

15. S. Hilic. Ph.D. thesis, University Blaise Pascal, Clermont-Ferrand, France (2000). 